Tropical Journal of Pharmaceutical Research October 2021; 20 (10): 2179-2185

ISSN: $1596-5996$ (print); 1596-9827 (electronic) (C) Pharmacotherapy Group, Faculty of Pharmacy, University of Benin, Benin City, 300001 Nigeria.

\title{
Comparison of efficacy and safety of general anesthesia alone with those of combined epidural/general anesthesia in Chinese patients with gastric cancer undergoing laparoscopy-assisted tumor resection
}

\author{
Hui Liu, Jie Wang, Hui Cao, Chao Zhang, Qingying Ma* \\ Department of Anesthesiology, Suzhou Ninth People's Hospital Soochow University, Suzhou, Jiangsu Province, China \\ *For correspondence: Email: ma987qingying@gmail.com, Tel/Fax: 0086-13255195686

\begin{abstract}
Purpose: To compare postoperative opioid consumption, inflammatory response, survival/clinical outcomes and safety profile of epidural combined with general anesthesia (GA) versus GA in stage 1 gastric cancer patients undergoing surgical intervention by laparoscopy.

Method: Chinese patients with early-stage gastric cancer undergoing laparoscopic-assisted tumor resection were enrolled and received either epidural combined with general anesthesia (group EA + GA) or general anesthesia only (group GA) in allocation ratio of 1:1. The following efficacy variables were assessed: 1) Pain score was measured on VAS scale; 2) post-operative consumption; 3) Quality of recovery; 4) inflammatory response; and 5) survival outcome. Safety was assessed throughout the study period.

Results: Data for 200 subjects were analyzed. Compared to GA alone, combination of EA + GA demonstrate significantly greater reduction in post-operative pain with decrease postoperative opioid consumption. Also, the combination of $G A$ and EA inhibited inflammatory response when compared to patients who received GA only. Moreover, the combination of GA and EA did not demonstrate any clinical benefit in survival outcome, when compared to patients who received GA alone, indicating that GA + EA has no role in improving survival outcome among patients undergoing gastric cancer surgery. Additionally, EA + GA was also associated with a shorter length of hospital stay, compared to GA. Conclusion: Overall, the results favor the use of GA + EA in Chinese patients with early-stage gastric cancer undergoing laparoscopic-assisted tumor resection. GA + EA combination improves immune response by inhibiting the inflammatory response but has no significant effect on survival outcome.
\end{abstract}

Keywords: Inflammatory response, General anesthesia, Epidural anesthesia, Gastric cancer, Survival, Postoperative opioid consumption

This is an Open Access article that uses a funding model which does not charge readers or their institutions for access and distributed under the terms of the Creative Commons Attribution License (http://creativecommons.org/licenses/by/4.0) and the Budapest Open Access Initiative (http://www.budapestopenaccessinitiative.org/read), which permit unrestricted use, distribution, and reproduction in any medium, provided the original work is properly credited.

Tropical Journal of Pharmaceutical Research is indexed by Science Citation Index (SciSearch), Scopus, International Pharmaceutical Abstract, Chemical Abstracts, Embase, Index Copernicus, EBSCO, African Index Medicus, JournalSeek, Journal Citation Reports/Science Edition, Directory of Open Access Journals (DOAJ), African Journal Online, Bioline International, Open-J-Gate and Pharmacy Abstracts

\section{INTRODUCTION}

Gastric cancer (GC) is one of the leading causes of mortality and morbidity and add significantly financial burden to patient and their family on healthcare [1]. The incidence of gastric cancer continues to increase in China, therefore there is unmet need of promising treatment modalities. Of available treatment modalities for treating early stage of GC, radical surgery is the choice of 
surgical intervention indicated for resectable GC of early stage [2]. During the surgical intervention, surgical cuts affect the modulation of several inflammatory biomarkers such as cytokines, which causes inflammatory reactions, which greatly influence the efficacy of treatment and causes poor prognosis including overall survival [3,4]. Thus, controlling inflammatory reactions and protecting immune function during perioperative period is essential to achieve targeted therapeutic response in cancer patients [5].

Several studies reported interesting finding on the role of anesthetic techniques in improving prognosis of GC and reducing the post-operative complications in GC patients undergoing surgical resection of tumor [6]. However, few studies reported that there was no relationship between anesthetic techniques and clinical prognosis of tumor. Zhong et al. reported that the combination of epidural anesthesia (EA) and general anesthesia (GA) (EA plus GA) improved the prognosis of tumor post-surgical interventions of ovarian cancer [7]. Christopherson and coworkers showed that there is no long-term benefits of overall survival and disease free survival outcome after surgical interventions of colon cancer using EA and GA [8].

In China, there is no study comparing postoperative opioid consumption, inflammatory response, survival/clinical outcomes and safety profile of EA plus GA versus GA in stage 1 gastric cancer patients undergoing surgical intervention using laparoscopy available. Considering the unavailability of clinical data on usage of $E A+G A$ and $G A$ in Chinese population undergoing surgical intervention for gastric cancer, and controversy in the results of clinical trial for these techniques of an aesthesis, the present study was designed to compare postoperative opioid consumption, inflammatory response, survival/clinical outcomes and safety profile of EA plus GA versus GA in stage 1 gastric cancer patients undergoing surgical intervention using laparoscopy.

\section{METHODS}

\section{Patients and ethics}

Chinese patients diagnosed with early-stage gastric cancer undergoing laparoscopic-assisted tumor resection were informed about the study procedures, role and responsibility of subject and investigator, then enrolled at study site after obtaining their written informed consent. The study was initiated after obtaining ethical approval from the institutional review board (IRB) of Soochow University, vide, IRB approval no. IRB/SU-19-S238/R548. The study was conducted in line with the ethical principles laid down in the Helsinki Declaration and its later amendments [9]. To assess the eligibility criteria, each subject was subjected into screening visit, where blood samples for complete laboratory assessment including chest $x$-ray, and electrocardiogram to confirm the suitability of subject.

The patients with American Society of Anesthesiologists (ASA) score of $\geq 4$, had history of bleeding disorder, uncontrolled diabetes, heart diseases, mental disorder, chronic renal disease, sleep disorder, pleural adhesions, and has ipsilateral thoracic surgery were excluded. Also, patients with deformity in airways or spinal, or chest wall were also excluded. The patients with any other pathology likely to affect the outcome of study, and patients who received concomitant and contra-indicated medications, as well as patients undergoing any other form of surgery, were excluded.

\section{Treatment and study procedure}

Subjects who met eligibility criteria were enrolled and received either epidural combined with general anesthesia (group EA + GA) or general anesthesia (group GA) in allocation ratio of 1:1. Intravenous fentanyl was administered to all patients as pre-anesthetic medication. The patients were monitored thoroughly the operating room and included ECG, pulse oximetry, blood pressure and respiratory rate.

In EA + GA group, propofol (IV injection, 1 to 2 $\mathrm{mg} / \mathrm{kg}$ ), fentanyl (3 $\mathrm{\mu g} / \mathrm{kg})$, and rocuronium (0.6 $\mathrm{mg} / \mathrm{kg}$ ) were used to induce general anesthesia. Before inducing GA, an epidural catheter was inserted in L1 an L2 using the median/loss-ofresistance approach. Lidocaine (2\%) up to $3 \mathrm{ml}$ as test dose was administered using epidural catheter after getting negative aspiration results of blood and cerebrospinal fluid. Then second dose of ropivacaine $(0.7 \%)$ in $6-8 \mathrm{~mL}$ was administered via epidural catheter after induction of GA. Ropivacaine $(0.7 \%, 5 \mathrm{~mL})$ was administered every $1 \mathrm{~h}$ during surgery. All patients received sevoflurane and analgesic as a part of maintenance of anesthesia. In GA group, propofol (IV injection, 1 to $2 \mathrm{mg} / \mathrm{kg}$ ), fentanyl (3 $\mu \mathrm{g} / \mathrm{kg})$, and rocuronium $(0.6 \mathrm{mg} / \mathrm{kg}$ ) were used to induce general anesthesia. Mechanical ventilator was achieved with a total volume of $8 \mathrm{~mL} / \mathrm{kg}$, with positive end-expiratory pressure (PEEP) was 15 $+/-1 \mathrm{~cm} \mathrm{H}(2) \mathrm{O}$. Ondansetron was administered as prophylaxis against nausea and vomiting. All patients received patient-controlled analgesic 
after end of surgery. Each patient was given opioid analgesia using PCA pump, in which morphine $100 \mathrm{mg}$ in $100 \mathrm{~mL}$ of sodium chloride $0.9 \%$ (1 $1 \mathrm{mg}$ per $1 \mathrm{~mL}$ ), with PCA bolus dose of $0.5 \mathrm{~mL}(0.5 \mathrm{mg})-2.0 \mathrm{~mL}(2.0 \mathrm{mg})$, the lockout time was 5 minutes. After the surgical procedure, pain score on VAS scale were measured.

The following efficacy variables were assessed: Pain score was measured on VAS scale $(0-10)$ immediately after exiting the OT room, and at 3 , $6,12,24,48$ and $72 \mathrm{~h}$. The pain score was assessed by a blinded observer. Quality of recovery in both the group was assessed using QoL-15 tool. Also, inflammatory response and survival outcome was assessed. Also, blood sample from each patient was instantly before administration of anesthesia (T1), $2 \mathrm{~h}$ after starting operation (T2), instantly after surgery (T3), and thereafter after $24 \mathrm{~h}$ (T4), 48 (T5) and $72 \mathrm{hr}$ (T5) of surgery. Inflammatory markers such as CD3+, CD4+, CD8+, CD4+/CD8+, IL-1, hs CRP, TNF-alpha, IL-8, and CEA level were measured using standard method. Also, survival outcome was measured in both groups and was assessed after discharge. Each patient was followed up for at least 3 years after discharge. Demographic and baseline characteristics as covariates to affect survival outcome were taken into consideration using cox regression model with baseline covariates. Hazard ration with $p$ value and $95 \%$ confidence interval $(\mathrm{Cl})$ range were calculated. Other key variables assessed were: AUC of VAS score, opioid consumption, length of hospital stay, treatment satisfaction as measured using degree of pain control (using 5point Likert scale), and post-operative complications, blood loss, incidences of hypotension, and cardiopulmonary stability during surgery. Safety was assessed throughout the study period.

\section{Statistical analysis}

The present preliminary investigation designed to compare postoperative opioid consumption, inflammatory response, survival/clinical outcomes and safety profile of EA plus GA versus GA in stage 1 gastric cancer patients undergoing surgical intervention using laparoscopy. Since, the present study was designed as a pilot or preliminary investigation, thus, there is no formal calculation of sample size required. In the present preliminary investigation, we have planned to recruit at least 100 Chinese gastric cancer patients undergoing laparoscopy in each treatment group. The finding of present study may benefit the scientific community and helps to design large clinical trial across globe. Quantitative data were analyzed using t test or
Mann Whitney based on the normality of data. Categorical data were analyzed using chisquare/fisher exact test as appropriate considering the data size. KM curve was used to compare survival outcome of both the group. Cox regression model with baseline covariates. Hazard ration with $\mathrm{p}$ value and $95 \% \mathrm{Cl}$ range were calculated.

\section{RESULTS}

A total of 200 Chinese patients undergoing gastric surgery were enrolled after satisfying all the eligibility criteria. All the enrolled Chinese patients have completed the study as per the study protocol. Patient characteristic is presented in Table 1. Demography and baseline characteristic were similar in both groups.

Table 1: Patient characteristics

\begin{tabular}{|c|c|c|c|}
\hline Variable & $\begin{array}{l}\text { GA Group } \\
(\mathrm{N}=100)\end{array}$ & $\begin{array}{c}\text { GA + EA } \\
\text { Group } \\
(\mathrm{N}=100)\end{array}$ & $P$-value \\
\hline $\begin{array}{l}\text { Age } \\
\text { (years) }\end{array}$ & $57.2 \pm 3.1$ & 59. $4 \pm 4.2$ & $>0.05$ \\
\hline $\begin{array}{l}\text { Weight, } \\
\text { kg }\end{array}$ & $67.2(3.6)$ & $69.2(5.6)$ & $>0.05$ \\
\hline $\begin{array}{l}\mathrm{BMI} \\
\left(\mathrm{kg} / \mathrm{m}^{2}\right)\end{array}$ & $27.2(1.3)$ & $26.6 \pm 2.1$ & $>0.05$ \\
\hline $\begin{array}{l}\text { Gender } \\
(\mathrm{M} / \mathrm{F})\end{array}$ & $75 / 35$ & $70 / 40$ & $>0.05$ \\
\hline \multicolumn{4}{|c|}{ ASA class (\%) } \\
\hline I & 21 & 23 & $>0.05$ \\
\hline II & 49 & 46 & \\
\hline II & 30 & 31 & \\
\hline $\begin{array}{l}\text { Tumor size, } \\
\mathrm{cm}\end{array}$ & $1.4(0.6)$ & $(0.9)^{1.5}$ & $>0.05$ \\
\hline $\begin{array}{l}\text { Anesthesia } \\
\text { time (min) }\end{array}$ & $\begin{array}{l}276.23 \\
(23.1)\end{array}$ & $\begin{array}{l}316.23 \\
(23.1)\end{array}$ & $>0.05$ \\
\hline $\begin{array}{l}\text { Surgical time } \\
\text { (time) } \\
\text { Stage }\end{array}$ & $\begin{array}{l}231.2 \\
(21.3)\end{array}$ & $\begin{array}{l}236.2 \\
(21.3)\end{array}$ & $>0.05$ \\
\hline I & 87 & 87 & $>0.05$ \\
\hline II & 10 & 10 & $>0.05$ \\
\hline Ila & 3 & 3 & $>0.05$ \\
\hline
\end{tabular}

As indicated in Table 2, the patients of both the treatment group had greater reduction in postoperative pain score at each time points. However, reduction in VAS score was significantly greater in patients who received GA + EA group as compared to patients who received GA group. At early time points, pain score after was significantly lower in patients who received epidural anesthesia combined with general anesthesia as compared to general 
anesthesia alone. Similar trend of results was found after 48 and $72 \mathrm{~h}$ of treatment (Table 2).

Table 2: Pain score assessed using VAS

\begin{tabular}{lccc}
\hline $\begin{array}{l}\text { Time } \\
\text { (h) }\end{array}$ & $\begin{array}{c}\text { GA Group } \\
(\mathbf{N}=\mathbf{1 0 0 )}\end{array}$ & $\begin{array}{c}\text { GA + EA } \\
\text { Group } \\
\mathbf{( N = 1 0 0 )}\end{array}$ & P-value \\
\hline 3 & $7.2(2.2)$ & $6.2(1.2)$ & $<0.005$ \\
6 & $6.8(2.1)$ & $5.8(1.3)$ & $<0.005$ \\
12 & $5.3(2.1)$ & $3.5(1.2)$ & $<0.005$ \\
24 & $5.6(1.8)$ & $3.2(1.3)$ & $<0.005$ \\
48 & $4.6(1.2)$ & $3.2(1.1)$ & $<0.005$ \\
72 & $3.2(0.9)$ & $1.2(0.8)$ & $<0.005$ \\
\hline Values & expressed as mean (SD) for & numerical \\
variable. P-value is based on Unpaired t test
\end{tabular}

This was further confirmed by postoperative opioid consumption, which was significantly lower in patient who received combination of epidural and general anesthesia as compared to combination of epidural and general anesthesia from day 1 to 4 (Table 3 ).

Table 3: Comparing opioids consumption postoperatively

\begin{tabular}{lccc}
\hline Day & $\begin{array}{c}\text { GA Group } \\
(\mathbf{N}=\mathbf{1 0 0 )}\end{array}$ & $\begin{array}{c}\text { GA + EA } \\
\text { Group } \\
(\mathbf{N}=\mathbf{1 0 0 )}\end{array}$ & $\boldsymbol{P}$-value \\
\hline Day 1 & $45(3.5)$ & $23(1.1)$ & $<0.005$ \\
Day 2 & $38(6.5)$ & $14(1.1)$ & $<0.005$ \\
Day 3 & $34(7.5)$ & $9(1.4)$ & $<0.005$ \\
Day 4 & $27(4.8)$ & $8.5(1.5)$ & $<0.005$ \\
\hline Values & expressed as mean (SD) for & numerical \\
variable. $P$-value is based on Unpaired t test
\end{tabular}

Postoperative opioid consumption was significantly higher in patients who received combination of epidural and general anesthesia as compared to general anesthesia (Table 3). Moreover, number of doses of diclofenac taken post-operatively was significantly higher among patients received general anesthesia alone as compared to patients received combination of epidural and general anesthesia (Table 4). The length of hospital stay was also slightly longer in patients received combination of epidural and general anesthesia as compared to general anesthesia (Table 4). In addition, degree of pain control satisfaction was higher in patients received combination of epidural and general anesthesia as compared to general anesthesia.
The percent viable $\mathrm{CD} 3+, \mathrm{CD} 4+, \mathrm{CD} 8+$ and CD4+/CD8 ratio were marginally increased in patients treated with combination anesthesia as compared to GA alone at all the timepoints (Table 5).

Overall, the level of inflammatory biomarkers such as IL-1, hs CRP, TNF-alpha, IL-8, and CEA level was significantly lesser in patients received combination of EA and GA as compared to those patients who received only GA (Figure 2).

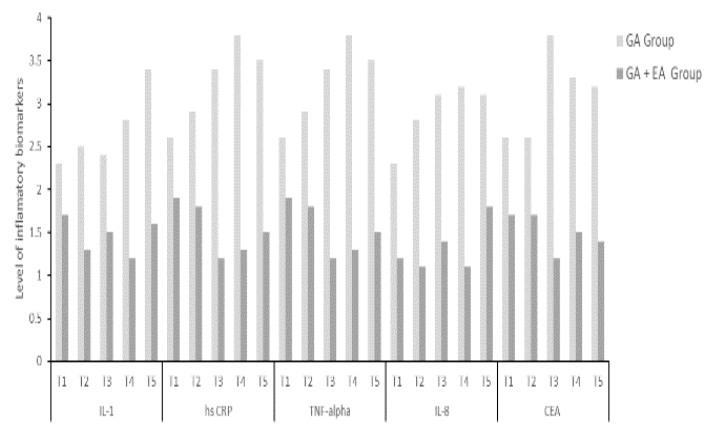

Figure 2: Summary of inflammatory biomarkers in patient Chinese patients with early-stage gastric cancer undergoing laparoscopic-assisted tumor resection

Survival outcome in both the treatment group were comparable in both groups irrespective of type of anesthesia used during surgical intervention for gastric cancer. This indicates that use of anesthesia does not have any effect on survival outcome of gastric cancer patient. Moreover, combination of GA + EA significantly improves the recovery time in patient undergoing laparoscopic-assisted tumor resection as compared to patients treated with GA only. Overall, incidence of nausea and vomiting was found comparable in both the groups. Postoperative results showed that the patients of both the group had comparable post-operative complications. The most common post-operative complications in patients of both the group were nausea/vomiting and CVS related complications followed by neurological related complication which were mild in severity. There was no statistically significant difference between both the groups with regard to post-operative complications.

Table 4: Summary of other endpoints

\begin{tabular}{lccc}
\hline Variable & GA group(N=100) & GA + EA group (N=100) & $\boldsymbol{P}$-value \\
\hline Incidence of nausea and vomiting, \% & 24.4 & 25 & $>0.05$ \\
Degree of pain control satisfaction & $3.1(0.5)$ & $4.2(0.4)$ & $<0.005$ \\
Diclofenac dose (mg) & $55.6(6.4)$ & $25(4.3)$ & $<0.005$ \\
Length of hospital stay (in days) & $6(1)$ & $5(1)$ & $<0.005$ \\
\hline
\end{tabular}

Values expressed as mean (SD) for numerical variable. $P$ value is based on Un paired test 
Table 5: Summary of $\mathrm{T}$ lymphocyte subcategories in patient Chinese patients with early-stage gastric cancer undergoing laparoscopic-assisted tumor resection

\begin{tabular}{|c|c|c|c|}
\hline Variable & $\begin{array}{c}\text { GA group } \\
(\mathrm{N}=100)\end{array}$ & $\begin{array}{c}\text { GA + EA } \\
\text { group } \\
(\mathrm{N}=100)\end{array}$ & $\begin{array}{c}P- \\
\text { value }\end{array}$ \\
\hline \multicolumn{4}{|l|}{$C D 3+, \%$} \\
\hline $\mathrm{T} 1$ & 53 & 54 & $>0.05$ \\
\hline $\mathrm{T} 2$ & 46 & 53 & $<0.5$ \\
\hline T3 & 35 & 48 & $<0.05$ \\
\hline T4 & 32 & 42 & $<0.05$ \\
\hline T5 & 31 & 39 & $<0.05$ \\
\hline \multicolumn{4}{|l|}{$C D 4+, \%$} \\
\hline $\mathrm{T} 1$ & 43 & 45 & \multirow{2}{*}{$\begin{array}{l}<0.05 \\
<0.05\end{array}$} \\
\hline T2 & 38 & 43 & \\
\hline T3 & 32 & 34 & $<0.05$ \\
\hline $\mathrm{T} 4$ & 27 & 34 & $<0.05$ \\
\hline T5 & 22 & 27 & $<0.05$ \\
\hline \multicolumn{4}{|l|}{$C D 8+, \%$} \\
\hline $\mathrm{T} 1$ & 23 & 24 & $>0.05$ \\
\hline $\mathrm{T} 2$ & 24 & 26 & $>0.05$ \\
\hline T3 & 21 & 19 & $>0.05$ \\
\hline 4 & 28 & 27 & $>0.05$ \\
\hline $\mathrm{T} 5$ & 15 & 14 & $>0.05$ \\
\hline \multicolumn{4}{|c|}{$\begin{array}{l}C D 4+/ C D 8 \\
\text { ratio }\end{array}$} \\
\hline T1 & 1.7 & 2.1 & $<0.05$ \\
\hline T2 & 1.1 & 1.9 & $<0.05$ \\
\hline T3 & 1.2 & 1.8 & $<0.05$ \\
\hline $\mathrm{T} 4$ & 1.2 & 1.9 & $<0.05$ \\
\hline T5 & 1.03 & 1.9 & $<0.05$ \\
\hline
\end{tabular}

\section{DISCUSSION}

The present study results report that the level of inflammatory biomarkers such as IL-1, hs CRP, TNF-alpha, IL-8, and CEA level was significantly lesser in patients received combination of $E A$ and GA as compared to those patients who received only $G A$. This indicates that response by decreasing IL-1, hs CRP, TNF-alpha, IL-8, and CEA levels. Also, treatment with GA and EA improves the level of $T$ lymphocyte such as CD3+, CD4+, and CD8+. The result of present study was consistent with the previous reports that combination of GA and EA inhibits inflammatory response as compared to patients received GA only, which indicates that GA + EA improves immune response in patient undergoing surgical intervention [10-14]. It has been reported that increase level of inflammatory biomarkers such as cytokines increases immunosuppressive properties, that results in tumor relapse and metastasis, that substantially reduced the survival period of cancer patients. Thus, controlling inflammatory reactions and protecting immune function during perioperative period is essential to achieving targeted therapeutic response in cancer patients.
This study results report that the patients of both treatment group had greater reduction in postoperative pain score at each time points. At early timepoints, pain score after was significantly lower in patients who received epidural anesthesia combined with general anesthesia as compared to general anesthesia alone. Similar trend of results was found after 48 and $72 \mathrm{~h}$ of treatment. This indicates that the combination of epidural and general anesthesia demonstrates significantly greater reduction in postoperative pain as compared to general anesthesia. This was further confirmed by postoperative opioid consumption, which was significantly lower in patient who received combination of epidural and general anesthesia as compared to combination of epidural and general anesthesia from day 1 to 4. Moreover, combination of $\mathrm{GA}+\mathrm{EA}$ significantly improves the recovery time in patient undergoing laparoscopic-assisted tumor resection as compared to patients treated with GA only.

The result of present study was consistent with the previous reports that the combination of GA and EA inhibits inflammatory response as compared to patients received GA only, which indicates that GA+EA improves immune response in patient undergoing surgical intervention. The result of present study was consistent with the previous reports that combination of GA and EA demonstrates significantly greater pain relief as compared to patients received $\mathrm{GA}$ alone, which indicates that $\mathrm{GA}+\mathrm{EA}$ improves pain relief and improve recovery among the patient undergoing surgical intervention [10-14].

During surgical intervention, several pain management options are available such as patient-controlled analgesia (PCA), regional analgesia and regional anesthesia including epidural that are more commonly used to manage post-operative pain. Opioids analgesics as PCA such as morphine and other derivatives are most frequently used primary treatment as analgesia in patient undergoing major surgical intervention such as cancer surgery. However, the use of Opioids PCA are commonly associated with adverse events such as sedation, nausea/vomiting, and pruritus.

In this study, survival outcome in both treatment group were found comparable in both the group irrespective of type of anesthesia being used during surgical intervention of gastric cancer. The result of present study was consistent with the previous reports that combination of GA and EA demonstrates no clinical benefit in survival outcome as compared to patients received GA 
alone, which indicates that GA + EA has no role in improving survival outcome among the patient undergoing surgical intervention [10]. The use of $E A$ in gastric cancer surgery is increasing nowadays due to its effect on metastasis/relapse of tumor postoperatively. Also, EA is likely to reduce the incidence of side effects and metastasis/relapse of tumor. Also, general anesthesia (GA) is commonly used gastric cancer surgical innervations.

The choice of anesthesia is vital in surgical intervention while performing surgical resection of tumor as it affects recovery, side effects and metastasis/relapse of tumor. Several studies have reported interesting findings on role of anesthetic techniques in improving prognosis of GC and reducing the post-operative complications in GC patients undergoing surgical resection of tumor. However, few studies reported that there was no relationship of anesthetic techniques and clinical prognosis of tumor. Zhong et al reported that the combination of EA and GA (EA plus GA) could improve the prognosis of tumor post-surgical interventions of ovarian cancer [7]. Christopherson and his coworkers showed that there are no long-term benefits of overall survival and disease-free survival outcome after surgical interventions of colon cancer using EA and GA [8]. The present study reports are consistent with the finding of Christopherson and his co-workers [8].

\section{Limitations of the findings}

Since the present trial was conducted at a single hospital in China, the findings of the present trial cannot be generalized to the Chinese population. Due to lower sample size, the power of trial was less; hence, a large clinical trial with appropriate sample size is needed to confirm the present findings.

\section{CONCLUSION}

When compared to GA alone, the combination of $\mathrm{EA}+\mathrm{GA}$ demonstrates significantly greater reduction in post-operative pain with decreased postoperative opioid consumption. Furthermore, the combination inhibits inflammatory response, when compared to patients who received GA only, which indicates that GA+EA improves immune response in patients undergoing surgical intervention. Moreover, combination does not demonstrate any clinical benefit in survival outcome, compared to patients who received GA alone, thus indicating that $\mathrm{GA}+\mathrm{EA}$ plays no role in improving survival outcome among patients undergoing gastric surgery.

\section{DECLARATIONS}

\section{Conflict of Interest}

No conflict of interest associated with this work.

\section{Contribution of Authors}

The authors declare that this work was done by the authors named in this article and all liabilities pertaining to claims relating to the content of this article will be borne by them.

\section{Open Access}

This is an Open Access article that uses a funding model which does not charge readers or their institutions for access and distributed under the terms of the Creative Commons Attribution License (http://creativecommons.org/licenses/by/ 4.0) and the Budapest Open Access Initiative (http://www.budapestopenaccessinitiative.org/rea d), which permit unrestricted use, distribution, and reproduction in any medium, provided the original work is properly credited.

\section{REFERENCES}

1. Choi WJ, Baek S, Joo EY, Yoon SH, Kim E, Hong B, Hwang JH, Kim YK. Comparison of the effect of spinal anesthesia and general anesthesia on 5-year tumor recurrence rates after transurethral resection of bladder tumors. Oncotarget 2017; 8: 87667-87674,.

2. Mahle WT, Matthews E, Kanter KR, Kogon BE, Hamrick SE, Strickland MJ. Inflammatory response after neonatal cardiac surgery and its relationship to clinical outcomes. Ann Thorac Surg 2014; 97: 950-956,.

3. Cheng YC, Cheng XB, Li XJ, Wang FZ, Li ZK: Combined general and regional anesthesia and effects on immune function in patients with benign ovarian tumors treated by laparoscopic therapy. Int J Clin Exp Med 2013; 6: 716-719.

4. Zhang $T$, Fan $Y$, Liu $K$, Wang $Y$. Effects of different general anaesthetic techniques on immune responses in patients undergoing surgery for tongue cancer. Anaesth Intensive Care 2014; 42: 220-227.

5. Cummings KC III, Patel M, Htoo PT. A Comparison of the effects of epidural analgesia versus traditional pain management on outcomes after gastric cancer resection. Reg Anesth Pain Med 2014; 39: 200-207

6. Cummings KC, XU F, Cummings LC, Cooper GS. A comparison of epidural analgesia and traditional pain management effects on survival and cancer recurrence after colectomy: A population-based study. Anesth 2012; 116: 797-806

7. Zhong S, Zhong X, Liu Y. Comparison between the effect of epidural anesthesia combined with epidural analgesia and general anesthesia combined with intravenous

Trop J Pharm Res, October 2021; 20(10): 2184 
analgesia on prognosis of ovarian cancer patients. Oncol Lett 2019;17(6):5662-5668.

8. Christopherson $R$, James KE, Tableman M. Long-term survival after colon cancer surgery: $A$ variation associated with choice of anesthesia. Anesth Analg 2008; 107(1): 325-332.

9. World Medical Association Declaration of Helsinki. Recommendations guiding physicians in biomedical research involving human subjects. JAMA 1997; 277:925-926.

10. Jiangling Wang. Impact of Combination Epidural and General Anesthesia on the Long-Term Survival of Gastric Cancer Patients: A Retrospective Study. Med Sci Monit 2016; 22: 2379-2385.

11. Bao-Jun Hou, Du Y, Shu-Xin G, Fan J, Wang R, Deng H, Guo DX, Wang Li, Yan-Ying Wang YY. General anesthesia combined with epidural anesthesia maintaining appropriate anesthesia depth may protect excessive production of inflammatory cytokines and stress hormones in colon cancer patients during and after surgery. Medicine (Baltimore) 2019;98(30):e16610.

12. Si-Yang Y, Xian-Jie Z, Yu-Kai Z. Effect of general anesthesia combined with epidural anesthesia on stress response, inflammatory reaction and coagulation in patients with colon Cancer. J. Hainan Med. Univ 2018; 24(18): 59-63

13. Liu W, Wu L, Zhang M. Effects of general anesthesia with combined epidural anesthesia on inflammatory response in patients with early-stage gastric cancer undergoing tumor resection. Exp. Ther. Med 2019;17: $35-40$,

14. Qin Liu. Effects of epidural combined with general anesthesia versus general anesthesia on quality of recovery of elderly patients undergoing laparoscopic radical resection of colorectal cancer: A prospective randomized trial. J Clin Anesth 2020; 62:109742. 